\title{
PULMONARY LAVAGE IN THE TREATMENT OF ALVEOLAR PROTEINOSIS
}

\author{
LiONel BusQue*
}

Pulmonary lavage is used in bronchial asthma, chronic bronchitis, ${ }^{1}$ and cystic fibrosis, ${ }^{2}$ but it has its greatest therapeutic value in alveolar proteinosis. It is not a new technique: in 1929, Garcia Vicente ${ }^{3}$ described a method of pulmonary lavage without outlining precisely all the indications or giving a detailed account of his findings.

In 1958, Rosen, Castelman and Liebow, in a masterly publication, gave the first description of alveolar proteinosis. ${ }^{+}$The treatment is empirical and the results are deceptive. ${ }^{5.8}$ In the mid-sixties, after his original description of segmental irrigation of the lung, ${ }^{5}$ Ramirez gave a description of a form of total washing of the lung that gave encouraging results. ${ }^{6}$ Since that time, this mode of treatment has been accepted as being the only valuable form of treatment, ${ }^{2}$ not only in serious cases with rapid progression but also in all other forms of the disease where it is serious enough to justify the treatment. Each treatment ordinarily involves a number of washings.

Two patients afflicted with this disease were referred to us. We have done a total of 14 pulmonary washings on them without complications or discomfort to patients.

The technique used is an adaptation of the technique described by Ramirez, ${ }^{6}$ and as modified by Dupont and Sphire, ${ }^{2}$ Wasserman ${ }^{11}$ and others.

Alveolar proteinosis is characterized by accumulation in the pulmonary alveoli of a proteinoceous substance rich in lipids, which does not produce any inflammatory response, but prevents gaseous exchange at the alveolar level and leads subsequently to severe respiratory insufficiency. ${ }^{4,7,8}$

However, this mode of treatment is delicate; these patients are seriously ill and they are almost always in severe respiratory insufficiency. The procedure involves flooding one lung with 1000 to $1500 \mathrm{ml}$ of fluid while the other lung is being ventilated with 100 per cent oxygen. Therefore, if serious complications such as acute anoxia, carbon dioxide narcosis, or cardiac failure are to be avoided, an exact understanding of the problems associated with the method as well as good control of the technique must be mastered.

We have treated two patients for a total of 14 pulmonary lavages. Mr. S. is a 40-year-old accountant with no major systemic illness except for his present complaint of dyspnoea on exertion. Mrs. S, a 27-year-old housewife showed no abnormality other than her pulmonary problem which prevented her from doing any manual housework.

"Lionel Busque, M.D., F.R.C.P.(C), Department of Anaesthesia, Ottawa General Hospital, 43 Bruyère Street, Ottawa, Canada K1N 5 C8. 
Mrs. S.

(a) Pulmonary Function

$\begin{array}{lcccc} & \text { VC } & \text { FRC } & \text { RV } & \text { TLC } \\ \text { (litres) } & \text { (litres) } & \text { (litres) } & \text { (litres) } \\ \text { Predicted } & 3.94 & 3.14 & 1.67 & 5.61 \\ \text { Measured } & 2.15 & 1.38 & .39 & 2.53\end{array}$

(b) Flow Rates

$\begin{array}{ccc} & \mathrm{FEV}_{1} & \mathrm{FEV}_{1} / \mathrm{FVC} \\ & \text { (litres) } & (\%) \\ \text { Predicted } & 3.30 & 86 \\ \text { Measured } & 1.89 & 87\end{array}$

Mr.S.

(a) Blood Gases (before lavage)

$$
\begin{array}{ll}
\mathrm{pH} & 7.4 \\
\mathrm{PCO}_{2} & 34.5 \mathrm{mmHg} \\
\mathrm{HCO}_{3} & 21.7 \mathrm{mEq} / \mathrm{L} \\
\mathrm{PO}_{2} & 64.9 \mathrm{mmHg} \\
\mathrm{O}_{2} \text { Sat } & 92.7 \%
\end{array}
$$

(b) Pulmonary Function

$\begin{array}{ccccc} & \begin{array}{c}\text { V.C. } \\ \text { (litres) }\end{array} & \begin{array}{c}\text { FRC } \\ \text { (litres) }\end{array} & \begin{array}{c}\text { RV } \\ \text { (litres) }\end{array} & \begin{array}{c}\text { TLC } \\ \text { (litres) }\end{array} \\ \text { Predicted } & 4.98 & 3.99 & 2.17 & 7.15 \\ \text { Measured } & 3.73 & 2.65 & 1.46 & 5.19\end{array}$

(c) Flow Rates

$\begin{array}{ccc} & \mathrm{FEV} & \mathrm{FEV}_{1} / \mathrm{FVC} \\ & \text { (litres) } & (\%) \\ \text { Predicted } & 3.75 & 77 \\ \text { Measured } & 3.35 & 93\end{array}$

Figure 1 shows the chest X-ray before lavage, and Figure 2 the chest X-ray after lavage.

The first pulmonary lavages reported by Ramirez ${ }^{6,9}$ were done using topical anaesthesia and with the patient breathing spontaneously. We chose general anaesthesia to avoid exposing the patient to a rather distressful procedure and to ensure adequate alveolar ventilation and oxygenation with controlled respiration. This also provides better washing conditions.

\section{Technique}

Premedication was achieved with a narcotic and an anticholinerigc. An intravenous infusion of glucose in distilled water was begun with a nylon catheter in a vein of the left forearm. The patient was connected to an electrocardiogram monitor and Lead I was monitored throughout the procedure. A 16-gauge catheter 

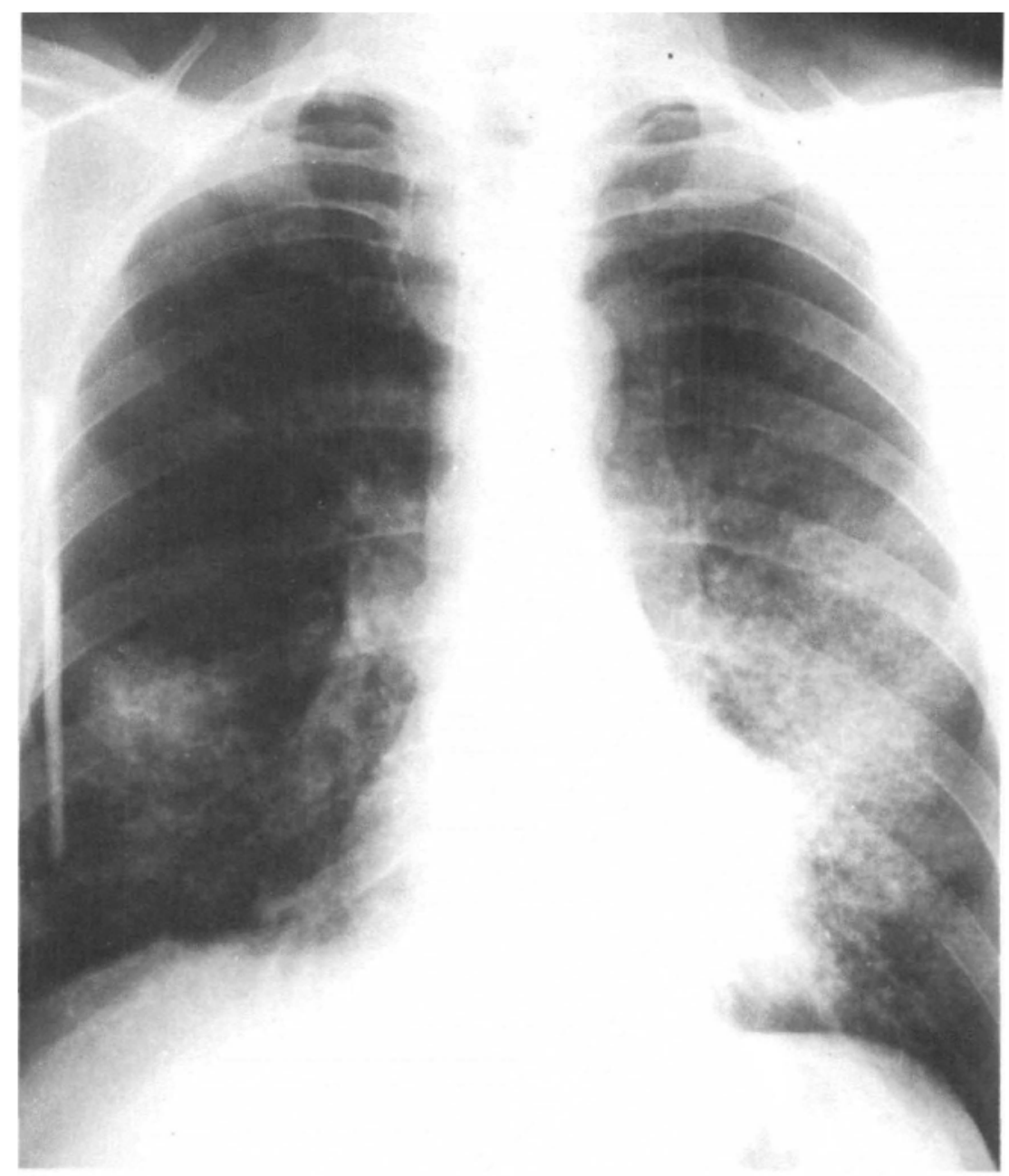

Ficure 1. Chest X-ray taken three weeks before lavage.

was then inserted in the left subclavian vein for rapid reading of the Central Venous Pressure (CVP).

A No. 21 scalp vein needle was inserted in the dorsalis pedis artery. This was attached to a three-way stopcock allowing rapid sampling for determination of arterial blood gases. The irrigating fluid for the arterial line was Lactated Ringer's solution with heparin 1000 I.U. in $500 \mathrm{ml}$.

The study consisted of a control period before induction of anaesthesia, followed by periods of denitrogenation, degasification and the actual lavage period. During each of these periods, the following parameters were recorded: blood pressure, pulse, central venous pressure (CVP) and arterial blood gas analysis.

Following the positioning of the patient on the operating-room table and a period of stabilization, control measurements were done. Anaesthesia was induced 


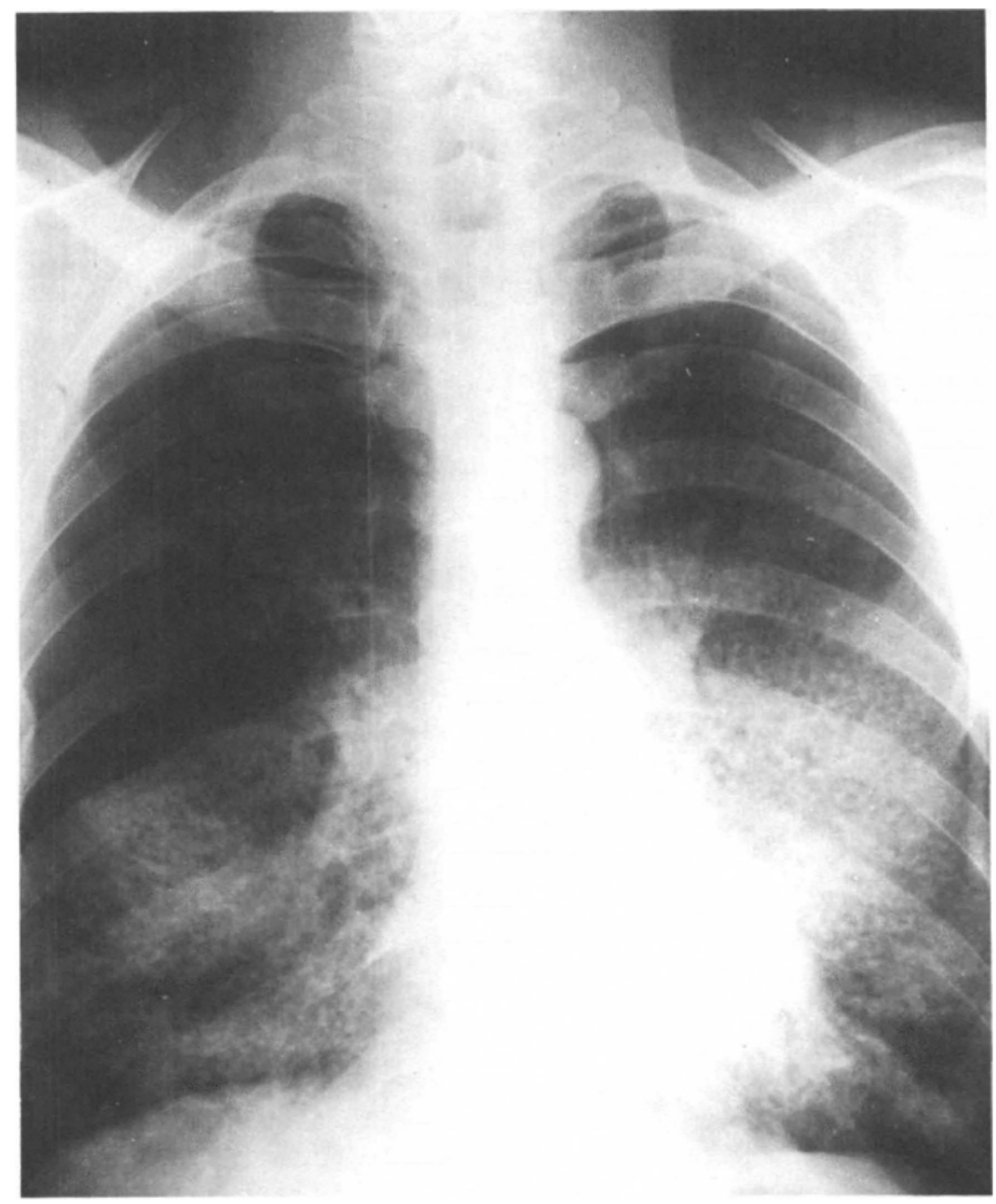

Figure 2. Chest X-ray taken three weeks after lavage. Note the poor remission following the series of four lavages.

with thiopentone $(5 \mathrm{mg} / \mathrm{kg}$ ), and the introduction of a Carlens double-lumen tracheal tube was facilitated with succinylcholine $(0.75-1.0 \mathrm{mg} / \mathrm{kg})$. The proper position of the tube was verified by auscultation of the chest and by a chest X-ray. As soon as the patient recovered from the initial paralysis, pancuronium $(0.05 \mathrm{mg} / \mathrm{kg})$ was injected and ventilation was then controlled using an Air Shields Anaesthesia Ventilator with an oxygen flow of 6 litres/minute. This continued for 20 minutes and is the period of denitrogenation.

The lumen of the Carlens tube on the side to be washed was then clamped for ten minutes, while the other lung was ventilated with 100 per cent oxygen. During this time the oxygen is absorbed from the non-ventilated lung; this is the period of "degasification". 


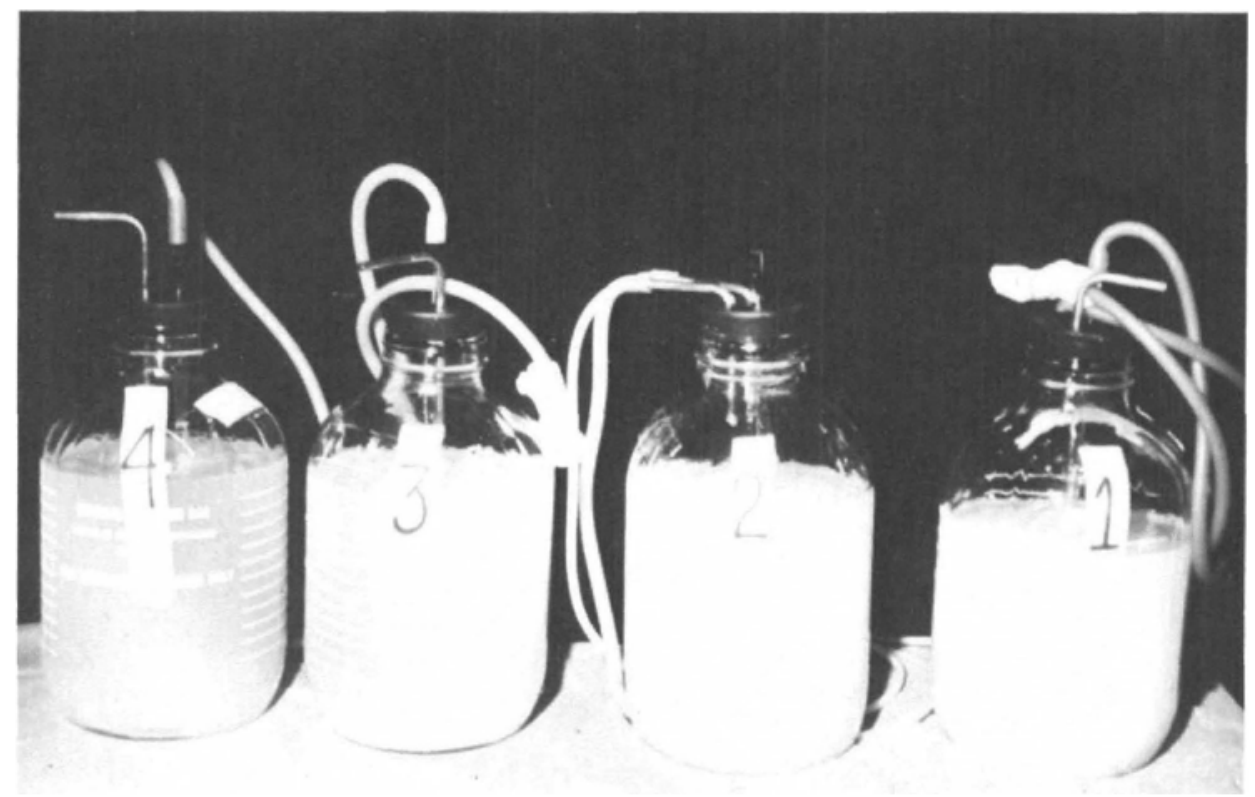

Figure 3. Drainage bottles. Note the clearing of lavage fluid as the lavage progresses.

The instillation of the lavage fluid follows degasification. Without allowing air to enter the lung, the lavage fluid flowed into the lung through one lumen of the Carlens tube, fed by gravity from a height not more than $25-29 \mathrm{~cm}$ above the midaxillary line. ${ }^{6}$ One litre of pre-warmed saline was run into the lung over a twominute period and then gravity-drained into sterile sealed bottles placed $60 \mathrm{~cm}$ below the mid-axillary line, the procedure taking three to four minutes (Figures $3,4)$. This was repeated ten to twelve times. During the washings, the cardiovascular and pulmonary status of the patient was carefully monitored. Auscultation of the lungs detects any fluid spill-over to the non-washed lung.

Respirator pressure up to 40 centimeters of water may be needed to achieve the six to eight litres per minute of ventilation necessary in the non-compliant unwashed lung. The other serious problems during lavage are hypotension ${ }^{6}$ and cardiac arrhythmias.

Throughout the procedure, anaesthesia is maintained with halothane 0.8 per: cent to 1.5 per cent and ventilation at six to eight litres per minute. We have used enflurane at 3 per cent to 1 per cent as an alternative to repeated exposure to balothane.

At the completion of the last lavage, the bronchial tree is emptied as completely as possible. This is accomplished by careful aspiration and with accurate measurement of the fluid balance. The patient is ventilated (both lungs) with oxygen at 100 per cent for ten minutes. The Carlens tube is then removed and a Portex tracheal tube is substituted. The patient is transported to the recovery room and 


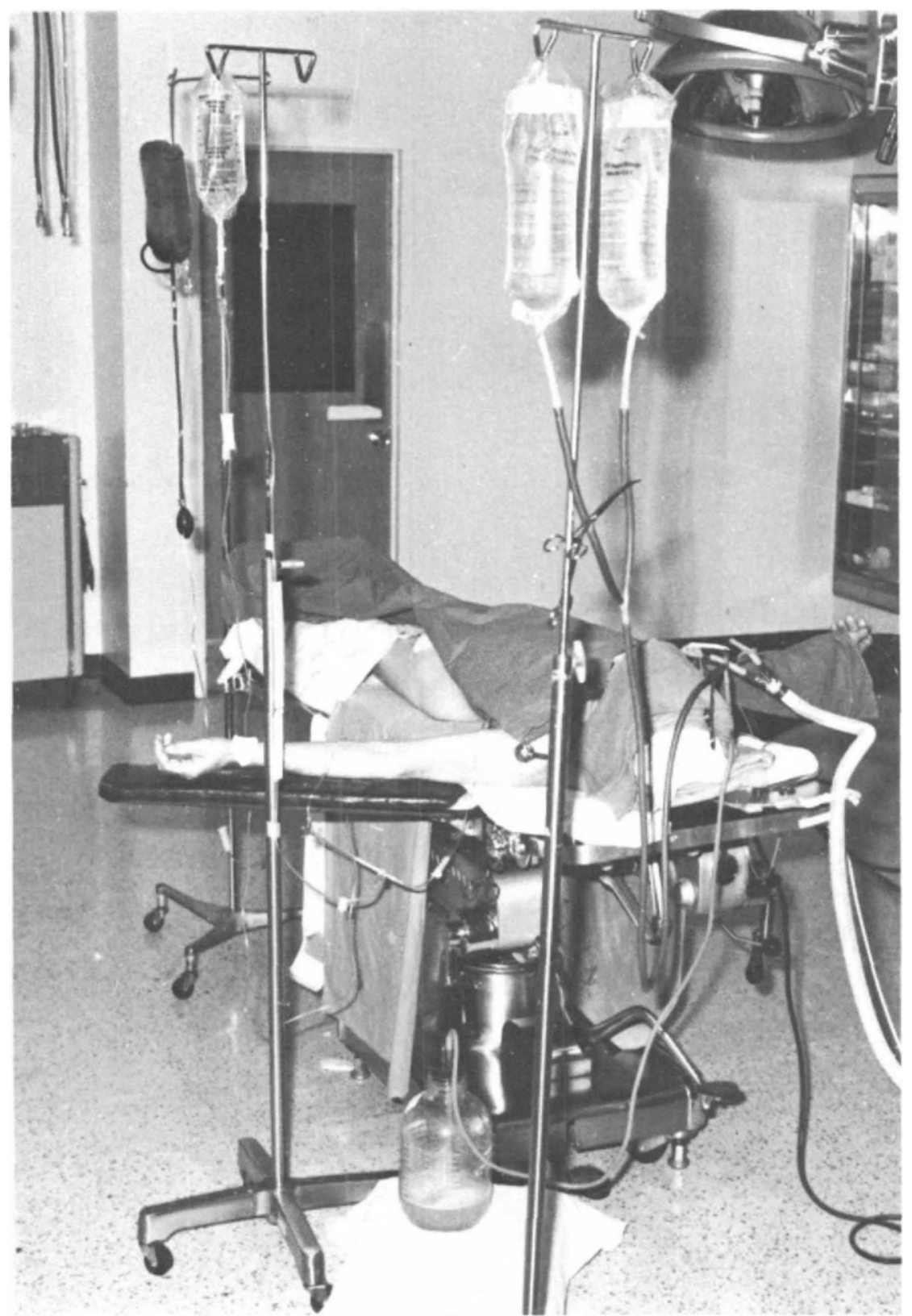

Figure 4. Set-up for right lung washing. Pre-warmed normal saline gravity-fed into right side of Carlen's tube.

ventilated with a Bennett MAI ventilator with an $\mathrm{FI}_{\mathrm{O}_{2}}$ of 0.6 . This is necessary to prevent the hypoxia reported to occur during the first two hours post-lavage. ${ }^{6}$

Frequent aspirations of the tracheobronchial tree are continued in the recovery room. This produces substantial amounts of thick viscous secretions. The patient 


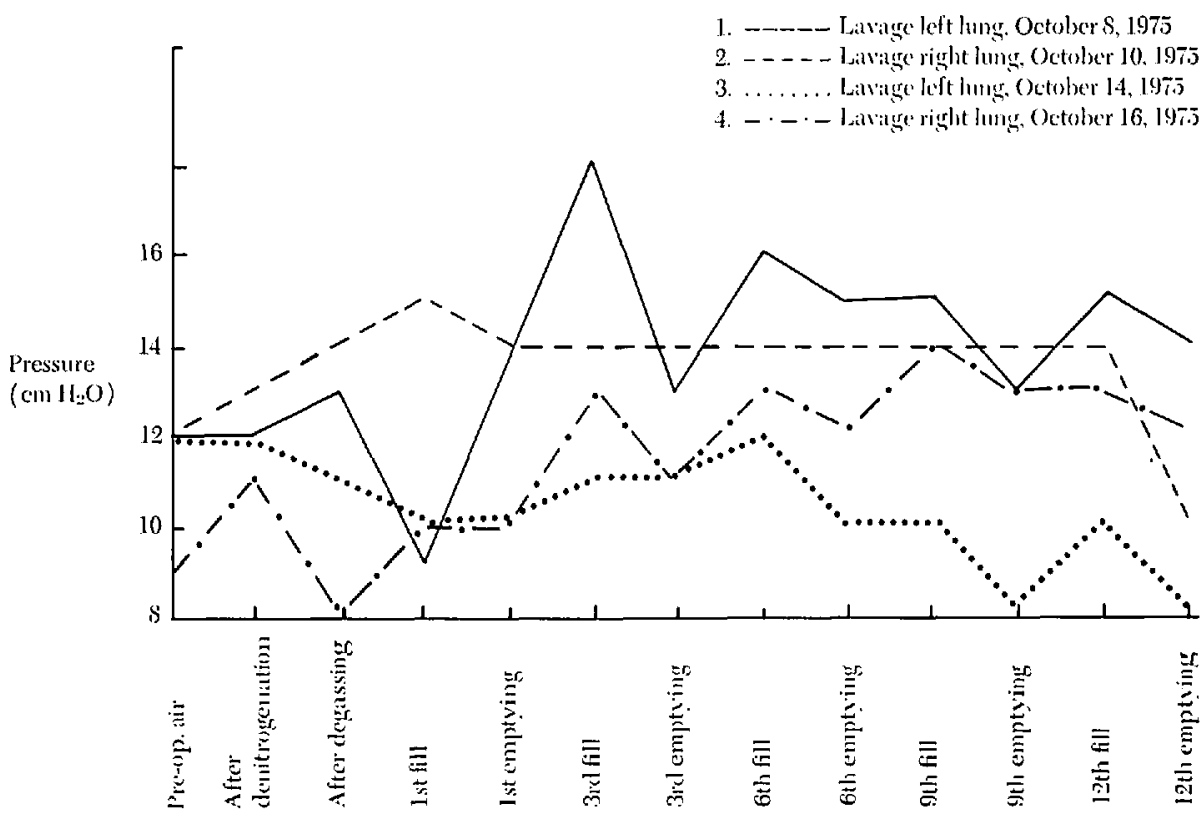

Ficune 5. Central Venous Pressure. Changes in C.V.P. during four successive lavages in one patient

is weaned progressively from the ventilator to a $\mathrm{T}$-piece (6 litres $\mathrm{O}_{2} / \mathrm{min}$ ) to spontaneous respiration after approximately two hours with the aid of frequent blood gas determinations. Following extubation, the patient is encouraged to take deep breaths and to cough, producing more thick white secretions. Once stabilized, the patient is returned to the floor, with the stay in the recovery room being three to four hours.

It has been shown that the benefits of this procedure are derived solely from the mechanical effects of the lavage. There is no advantage of the solution used by Ramirez ${ }^{912}$ over the pre-warmed saline.

\section{COMPLications}

We have noted the following complications in this rather demanding and tedious procedure:

(1) Induction of anaesthesia is usually uncomplicated. However, on one occasion, a resident using the Carlen's tube for the first time introduced it into the right main stem bronchus. This was immediately recognized by $\mathrm{X}$-ray and corrected.

(2) Choice of a bad tube. We originally chose to use the Carlen's for washing the left lung and the White tube for washing the right lung because these tubes intubate the right and left bronchi respectively. Two attempts done with the White tube were a failure. It was impossible for us to have a water-tight seal and the drainage of the lung was unsatisfactory. We then tried the Carlen's tube to wash the right lung, with no more problems. 


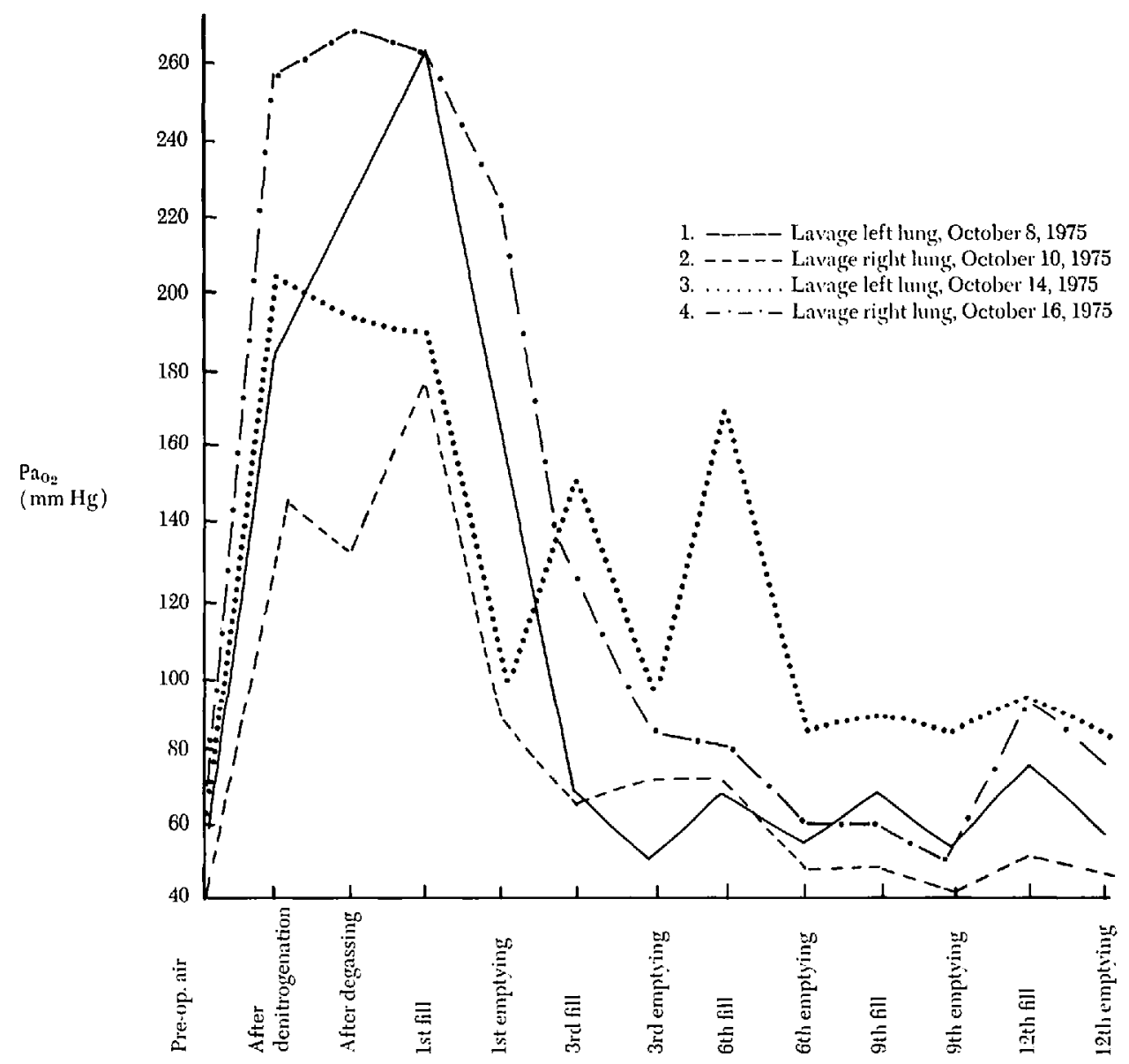

Figure 6. $\mathrm{Pa}_{0_{2}}$ variation in four successive lavages

(3) Malposition of the tube.

On at least two occasions, we had difficulty in draining the first litre of fluid infused into the lung, even though the position of the tube seemed to be perfect radiographically. The tube was repositioned and the procedure was completed without difficulty.

(4) Balloon cuffs may not be inflated enough. On at least one occasion, we had a spill of fluid from the washed lung to the ventilated lung. We also had difficulty in draining the lung because the cuff in the main stem bronchus was overinflated. All these problems were immediately recognized and rapidly corrected and the washing continued.

(5) Arrhythmia

On the last washing, after lavage, the patient suddenly presented bigeminy and multiple premature ventricular contractions. The $\mathrm{PaCO}_{2}$ was found to be 64 . This was corrected by increasing the ventilation. 
In theory, pulmonary lavage is supposed to produce a marked elevation of the CVP and the $\mathrm{Pa}_{\mathrm{O}_{2}}$ in every patient after infusion of the saline. On the other hand, when the lung is drained, the CVP and $\mathrm{Pa}_{\mathrm{O}_{2}}$ come back rapidly to baseline values. In fact, although this pattern predominates, it is very unstable as four successive curves in the same patient demonstrate.

\section{Discussion}

The instillation of large volumes of fluid into the lung produces an increase in the intrathoracic and intravascular pressure, a shift of the mediastinum away from the washed lung and, finally, loss of the capillary perfusion in those alveoli full of liquid. ${ }^{210}$ All these changes are a direct consequence of the mechanical effect of the lavage.

Increase of intrathoracic pressure is the result of the hydrostatic pressure created by the fluid column used for filling the lung. ${ }^{10}$ The increase of intravascular intrathoracic pressure is caused by the elevation of the intrathoracic pressure and compression of the large vessels by the shift of the mediastinum. Those changes of intrathoracic and intravascular pressure are responsible for the great variations of the $\mathrm{Pa}_{\mathrm{O}_{2}}{ }^{10}$

Other workers have established that the pulmonary capillaries are compressible vessels, and because of this fact are influenced by alveolar pressure. When the alveolar pressure exceeds mean pulmonary pressure, the pulmonary vessels are collapsed and circulation stops. ${ }^{10}$ This explains the spectacular increase in $\mathrm{Pa}_{\mathrm{O}_{2}}$ after the instillation of liquid in the lung. The lung is then not only not ventilated but also not perfused.

On emptying the lung, the regional arterial pressure again exceeds the alveolar pressure and circulation is re-established; this lung is again atelectatic, i.e. perfused but not ventilated and the $\mathrm{Pa}_{\mathrm{O}_{2}}$ falls.

Our two patients have been improved subjectively and radiographically by the procedure. Mrs. S has maintained this remission for a period of one and a half years after two lavages.

Mr. S, on the other hand, presents much more serious disease; he has been hospitalized on two different occasions for a series of lavages. It seems that, for him, the period of remission brought about by the lavage is about six months.

\section{SUMMARY}

Alveolar proteinosis is a rare disease characterized by the accumulation of a proteinoseous material inside the alveolus. Various forms of treatment have been tried without much success. Pulmonary lavage has been found effective in bringing relief to patients as well as objective amelioration. This presentation describes the technique used and the problems encountered.

\section{RÉSUMÉ}

La protéinose alvéolaire est une maladie rare caractérisée par l'accumulation d'un matériel protéiné à l'intérieur de l’alvéole pulmonaire. Diverses formes de 
traitement ont été essayées sans grand succès. Le lavage pulmonaire a soulagé subjectivement le patient et a, par ailleurs, amené une amélioration objective. Cette présentation décrit la technique employée dans le lavage pulmonaire et les problèmes rencontrés.

\section{ACKNOWLEDGMENTS}

Our thanks to Dr. David Skene whose collaboration was appreciated in the correction and revision of the text; Mrs. Roberts (Statistics Canada) who helped in preparing the graphics; Drs. Joyal and Tousignant whose contribution to this article is very much appreciated; and Mr. St. Laurent who prepared the photographs.

\section{REFERENCES}

1. Ramirez, J. \& OBescour, W.H, Bronchopulmonary lavage in asthma and chronic bronchitis. Chest, 59: 146-152 (1971).

2. Dupont, F.S. \& Sphire, R.D. Pulmonary lavage. Critical Care Medicine 161-162 (1974).

3. Vicente, G. Le lavage des poumons. Presse Médicale 78: 1266-1268 (1929).

4. Castremian, B., Rosen, S.H., \& Liebow, A.A. Pulmonary alveolar proteinosis. New England Journal of Medicine 258: 1123-1142 (1959).

5. Rasmez, J.R., Schultz, R.B., \& Dutton, R.E. Pulmonary alveolar proteinosis. New techniques and rationale for treatment. Archives of Internal Medicine 112: 419-431 (1963).

6. Ramirez, J.R. Bronchopulmonary lavage. Disease of chest, vol. 50, 6: 581-588 (1966).

7. Wasserman, K., Blank, N., \& Fletcher, G. Lung lavage in alveolar proteinosis. American Journal of Medicine 44: 611-617 (1968).

8. RaMirez, J.R. Alveolar proteinosis; importance of pulmonary lavage. American Review of Respiratory Disease 103: 666-678 (1971).

9. Raminez, J.R. Pulmonary alveolar proteinosis. Treatment by massive bronchopulmonary lavage. Archives Intern Medicine 119: 147-156 (1967).

10. SMith, J.D., Mullen, J.E., SAFar, P., \& Robin, E. Intrathoracic pressure, pulmonary vascular pressure and gas exchange during pulmonary lavage. Anesthesiology 33: 401-405 (1970).

11. Wassemian, K. \& Costley, B. Advances in the treatment of pulmonary alveolar proteinosis. American Review of Respiratory Disease 111: 361-363 (1975).

12. Koorilsky, R., Beauregard, J.M., \& Manzi, J. La protéinose alvéolaire. L’Union Médicale du Canada. Vol, 92: 1098-1107. 